\title{
Modelling the comet assay
}

\section{Darragh McArt*, Robert Cairns, Gillian Wasson and Kurt Saetzler}

\author{
Address: School of Biomedical Sciences, University of Ulster, Coleraine, BT52 1SA, Northern Ireland, UK \\ Email: Kurt Saetzler - k.saetzler@ulster.ac.uk \\ * Corresponding author
}

from BioSysBio 2007: Systems Biology, Bioinformatics and Synthetic Biology

Manchester, UK. II-I3 January 2007

Published: 8 May 2007

BMC Systems Biology 2007, I(SuppI I):P7I doi:10.1 I86/I752-0509-I-SI-P7I

This abstract is available from: http://www.biomedcentral.com/I752-0509/I?issue=SI

(C) 2007 McArt et al; licensee BioMed Central Ltd.

\section{Background}

The single cell gel electrophoresis or Comet assay is a sensitive, reliable, and quick fluorescent microscopic method for detecting DNA single-strand (SSBs) and double-strand breaks (DSBs) at an individual cell level [1]. In this assay, single cells are embedded in agarose on frosted slides, lysed to remove all cellular proteins, subjected to brief electrophoresis, stained with a DNA intercalating dye, and observed with fluorescence microscopy. Undamaged DNA is unable to enter the agarose gel, and is retained in the cavity formed by the lysed cell: damaged DNA streams down the electrophoretic field, and forms the "tail" of a Comet $[2,3]$. The length and fluorescent intensity of the Comet tail relates to the number of DNA-strand breaks. Undamaged cells appear as intact nuclei (Comet heads) without tails. The Comet assay has been implemented successfully over the years in the areas of genotoxicology [1], clinical studies, DNA repair studies [4], environmental and human biomonitoring [1].

\section{Modelling}

Despite the fact that the Comet methodology has been widely used for the last twenty years, there is still controversy over exactly how the assay works and how strongly the Comet shape correlates the number of DNA-strand breaks. In order to answer some of these questions, we established a simple statistical model of the Comet assay. It uses available and published data about chromatin loop sizes and chromosome lengths (in base pairs). It also considers different condensation factors depending on whether healthy (maximal condensation) or damaged DNA (SSBs or DSBs occurred) is simulated. After applying the electrophoretic field, the DNA gets pulled towards the anode, which orients the chromatin mainly along the electric field. Distributing the chromatin along this axis and recording the state of each loop (healthy, damaged), the type and frequency of the damage (SSBs or DSBs) finally generates a virtual Comet.

\section{Conclusion}

After the simulation has been performed, we create artificial microscopic images integrating the intensities of the fluorochromes along the optical axis and blurring the image using the point-spread function of the microscope. These virtual microscopic images can then visually be compared to real images of Comets of the same cell types. Having such a system in place allows repetition of these simulations for different cell types and creation of a set of test images that can be used to estimate the accuracy of existing Comet analysis software.

\section{References}

I. McKelvey-Martin VJ, Green MH, Schmezer P, Pool-Zobel BL, De Meo MP, Collins A: The single cell gel electrophoresis assay (comet assay): a European review. Mutat Res 1993, 288:47-63.

2. McKelvey-Martin VJ, Ho ET, McKeown SR, Johanson SR, McCarthy PJ, Rajab NF, Downes CS: Emerging applications of the single cell gel electrophoresis (Comet) assay. I. Management of invasive transitional cell human bladder carcinoma, II. Fluorescent in situ hybridization Comets for the identification of damaged and repaired DNA sequences in individual cells. Mutagenesis 1998, 13:1-8.

3. Fairbairn DW, Olive PL, O'Neill KL: The Comet assay: a comprehensive review. Mutat Res 1995, 339:37-59.

4. McKenna DJ, Rajab NF, McKeown SR, McKerr G, McKelvey-Martin V]: Use of the Comet-Fish assay to demonstrate repair of the TP53 Gene region in two human bladder carcinoma cell lines. Radiat Res 2003, I 59:49-56. 